\title{
LEIGOS E CATÓLICOS EM DISPUTA PELA ESCOLA NOVA NO BRASIL NA DÉCADA DE 1930
}

\author{
Macioniro Celeste Filho \\ Universidade Estadual Paulista Júlio de Mesquita Filho (UNESP), São \\ Paulo, São Paulo, Brasil
}

\begin{abstract}
Resumo: No Brasil, as ideias da Escola Nova foram apresentadas como propícias a um país moderno. Contudo, o que se entendia por Escola Nova? Na configuração da Escola Nova, dois grupos ganharam nitidez: o dos intelectuais com uma postura leiga face à sociedade e o dos intelectuais ligados à Igreja Católica. Duas obras de formação pedagógica, de 1932, são exemplares das divergências políticas em disputa. No atual trabalho, será abordada a concepção de Escola Nova leiga contida no livro Escola Moderna, de Maria dos Reis Campos. A concepção católica será tratada com o livro A Escola Nova, de Jonathas Serrano. A metodologia utilizada foi a de análise documental dos dois livros a serem abordados. $O$ objetivo do trabalho foi de propiciar a compreensão do contexto histórico quando das divergências intelectuais e institucionais sobre a conceituação de Escola Nova no Brasil da década de 1930.
\end{abstract}

Palavras-chave: Educação católica. Educação leiga. Escola Nova. História da Educação.

\section{A escola nOVa}

As ideias da Escola Nova foram apresentadas desde os anos 1920 como imprescindíveis para a renovação da educação brasileira e, consequentemente, como propícias para a reformulação da sociedade que se buscava criar, mais adequada a um país moderno. A visão do final do século XIX de que era a escola que formava a sociedade ganhou novo fôlego com os debates sobre a Escola Nova na década de 1930. Sinteticamente, a Escola Nova garantiria a superação do país arcaico, com o surgimento de uma sociedade nova, apta para levar o Brasil à modernidade. Contudo, se isto gradativamente se tornava um consenso entre a intelectualidade brasileira, o que se entendia então por Escola Nova? As concepções eram muito divergentes. Havia Escola Nova para todos os gostos. Conforme a concepção política e ideológica em questão, a Escola Nova ganhava contornos bem diferentes. Definir o que era a Escola Nova transformou-se em disputa privilegiada entre a intelectualidade brasileira nos anos 1930. Escola Nova e modernidade eram concebidas como duas faces da mesma moeda. Dependendo de qual modernidade se almejava, se pressupunha uma Escola Nova especificamente adequada a formar os sujeitos modernos para esta ou aquela nova sociedade. Entre os intelectuais em disputa pela Escola Nova, dois grupos distintos ganharam nitidez: o dos intelectuais com uma postura leiga face à sociedade e o dos 
intelectuais ligados à Igreja Católica. Este trabalho apresentará o movimento dos leigos e dos católicos no embate de convencimento intelectual dos profissionais que deveriam implantar os preceitos da Escola Nova no Brasil. A discussão sobre a Escola Nova foi contemporânea à modernização da produção de livros no Brasil e à expansão das bibliotecas escolares destinadas à formação docente. Duas obras de formação pedagógica, de 1932, são exemplares das divergências políticas em disputa. No atual trabalho, será abordada a concepção de Escola Nova leiga através da apresentação do livro Escola Moderna, de Maria dos Reis Campos. Para entender a concepção católica, será tratado o livro A Escola Nova, de Jonathas Serrano. Qual Escola Nova criaria o país moderno? Pretende-se expor aqui as concepções de modernidade divergentes no Brasil na década de 1930.

Segundo Marta Carvalho (2003, p. 4), as tentativas de implantação dos princípios da Escola Nova no Brasil diferem muito da experiência européia. Na Europa, este movimento articulou-se como crítica a um modelo escolar plenamente instituído. No Brasil, as propostas da Escola Nova se defrontaram com a inexistência de sistemas escolares em funcionamento na maior parte do país. Na década de 1930, havia uma proposta de redefinição sobre a finalidade social a que deveria tender o sistema educacional brasileiro. Segundo a autora, propunha-se que a Escola Nova deveria equacionar:

A sociedade nova, moderna, que as 'lições da [1ª] Guerra [Mundial]' faziam entrever como dependente de uma nova educação, redefinida em seus princípios e largamente baseada na ciência; temor da ascensão incontrolada das 'massas' e conseqüente investimento em medidas de 'racionalização' das relações sociais sob o modelo da fábrica; ênfase na escola e na expansão de seu raio de influência na sociedade, como recurso para contrapesar a força de 'contágio' dos novos meios de comunicação, controlando o fluxo inédito de idéias e imagens postas em circulação através do cinema, do rádio e do impresso de escala industrial (CARVALHO, 2001, p. 67).

Para tanto, intelectuais engajados no projeto de implantação da Escola Nova no Brasil desenvolveram estratégias de direcionar neste sentido as políticas educacionais concebidas com a criação do Ministério da Educação e Saúde Pública no final de 1930 e seus congêneres estaduais logo em seguida. Estes intelectuais ocuparam postos governamentais para viabilizar a implantação dos princípios da Escola Nova no país. Contudo, havia a necessidade de criação de um consenso sobre o que era a Escola Nova a ser implementada. No intuito de criação deste consenso, buscaram o convencimento dos profissionais da educação, principalmente os professores, através da edição de livros de formação pedagógica que apresentassem o que era esta tal de Escola Nova. Neste sentido, o embate pelo convencimento de que a Escola Nova deveria ser atributo de um Estado leigo ou ferramenta de uma educação cristã, conduzida pela Igreja Católica, dividiu a intelectualidade brasileira e a indústria editorial de livros de formação de professores.

Existiram outras coleções pedagógicas editadas em alguns dos demais estados do país, porém, a aglutinar os pressupostos de uma Escola Nova leiga, destacaram-se duas coleções de formação docente: a "Biblioteca de Educação", editada por Lourenço 
Filho desde 1927 para a Companhia Melhoramentos e a coleção "Atualidades Pedagógicas", editada desde 1931 por Fernando de Azevedo para a Companhia Editora Nacional, ambas de São Paulo. Maria Rita Toledo (2006, p. 341) analisou o papel de Lourenço Filho, de Fernando de Azevedo e de outros intelectuais frente à Escola Nova no período. Para esta autora, estes pensadores pretendiam reformar a cultura realizando uma ampla reforma educacional que modificasse a mentalidade das novas gerações das classes média e alta, através de uma educação que formasse a consciência nacional das elites do país, mas também que educasse as classes populares para que pudessem elevar seu nível econômico, moral e intelectual, proporcionando assim maior mobilidade social. Caberia à escola papel central neste processo de dinâmica social. Uma das estratégias para que isto ocorresse tinha por alvo o desenvolvimento intelectual dos professores das escolas primárias. Para tanto, devia-se aprimorar sua formação, principalmente selecionando melhor o que estes professores deveriam ler, com o objetivo de obter uma capacitação cultural condizente com os propósitos da Escola Nova. É com esta intenção que se pode compreender a atuação editorial de Lourenço Filho e Fernando de Azevedo. Segundo Marta Carvalho e Maria Rita Toledo (2007, p. 98), a renovação dos livros escolares por parte destas coleções, além de ser um negócio lucrativo, revestia-se de um caráter de intervenção político-cultural, fazendo circular os novos materiais recomendáveis à formação docente no crescente processo de escolarização do Brasil. Maria Rita Toledo (2003, p. 5) destaca que Fernando de Azevedo entendia a indústria moderna do livro como condição de acesso ao saber e à cultura, possibilitando a prática da autoeducação. Porém, para que isto ocorresse satisfatoriamente, a seleção das leituras deveria ser regrada e ordenada segundo prescrições que as tornassem apropriadas aos propósitos da escolarização moderna, eliminando o mal que práticas descoordenadas pudessem causar aos professores do sistema escolar em implantação e expansão. Em 1932, com a publicação do Manifesto dos Pioneiros da Educação Nova, redigido por Fernando de Azevedo, o grupo a defender uma Escola Nova leiga passou a ser chamado de "Pioneiros" ou também de "Renovadores".

Embora coordenassem coleções pedagógicas em editoras concorrentes, Lourenço Filho e Fernando de Azevedo encontravam-se do mesmo lado nos embates entre os "Pioneiros" e os "Católicos" no que concerne à natureza leiga das propostas da Escola Nova. Marta Carvalho (2001, p. 69-70) analisou estas disputas:

A criação do Ministério da Educação e Saúde [em 1930] inaugura espaços de poder de importância estratégica na configuração e no controle, técnico e doutrinário, do aparelho escolar. Com isso, o consenso em torno da "causa educacional" transmuda-se em disputa pela implementação de programas político-pedagógicos concorrentes. Nessa disputa, dois grupos se constituem, antagonizando-se a partir de propostas rivais de controle técnico e doutrinário das escolas: os 'católicos' e os 'pioneiros'. As nomeações designam, no caso do primeiro grupo, setores militantes do laicato intelectual católico que haviam integrado a ABE [Associação Brasileira de Educação] nos anos vinte e que a abandonaram em 1932, passando a se articular na Associação dos Professores Católicos do Distrito Federal, e no Centro D. Vital, de São Paulo, inicialmente, e, a partir de 1934, na Confederação Católica Brasileira de Educação. No caso do segundo, o nome designa alguns dos signatários do Manifesto dos Pioneiros da Educação Nova que assumiram o controle da Associação Brasileira de Educação a partir de 1932 e que ocuparam postos 
governamentais, na qualidade de técnicos, tomando iniciativas de reforma escolar pautadas na pedagogia escolanovista.

No Rio de Janeiro, reunindo os setores católicos que buscavam definir sob sua ótica o que deveria ser a Escola Nova, a editora Civilização Brasileira lançou uma coleção de livros destinada à formação docente denominada "Biblioteca Brasileira de Cultura". É intrigante constatar que o lucro editorial com a disputa polarizando o que se concebia como Escola Nova foi capitalizado por um mesmo empresário. Em 1932, Octalles Marcondes Ferreira, dono da Companhia Editora Nacional, que publicava a coleção "Atualidades Pedagógicas", coordenada desde o ano anterior por Fernando de Azevedo, emblemático expoente dos "Pioneiros", comprou a editora Civilização Brasileira, representante dos intelectuais católicos. Desde então, Octalles Marcondes Ferreira passou a lucrar nos dois lados editoriais da disputa entre "Pioneiros" e "Católicos":

Octalles Marcondes Ferreira, dono das duas editoras, divide o mercado editorial em duas frentes: [Companhia Editora] Nacional para os 'renovadores' ligados a [Fernando de] Azevedo e Civilização Brasileira para os 'católicos'. Assim, engloba os diferentes leitores inseridos no movimento educacional do período, trabalhando com diferentes referenciais de recomendação de leitura, num sentido, antagônicos, invadindo assim, por todos os lados, o novo mercado de livros para professor (TOLEDO, 2001, p. 62).

No atual trabalho pretende-se abordar duas obras emblemáticas da disputa entre leigos e católicos pela concepção do que deveria ser a Escola Nova. Elas não foram publicadas por nenhuma das três editoras anteriormente mencionadas. Este panorama editorial teve o propósito de contextualizar a produção das obras a serem tratadas neste artigo. É que ambas dialogaram com dois livros anteriores, que lhes serviram de referência ou de contraponto. Trata-se do livro Introdução ao estudo da Escola Nova, de Lourenço Filho, publicado em 1929 pela "Biblioteca de Educação", da Companhia Melhoramentos e o primeiro volume da coleção "Atualidades Pedagógicas", de 1931, Novos caminhos e novos fins, de Fernando de Azevedo; além, é claro, do Manifesto dos Pioneiros da Educação Nova, de 1932, deste mesmo autor.

\section{A PRODUÇÃO BIBLIOGRÁFICA SOBRE A ESCOLA NOVA NO BRASIL}

Segundo Marta Carvalho e Maria Rita Toledo, o livro de Lourenço Filho serviria de introdução às demais obras da coleção por ele organizada:

Na forma que estrutura o livro e que preside a organização da coleção, trata-se de fornecer um repertório de saberes autorizados, destinados a fundamentar a prática docente. Saberes selecionados e hierarquizados pela avaliação que Lourenço Filho faz das disposições, expectativas e competências de seu público leitor e pelos requisitos que identifica necessários à mudança que programa gradativamente promover 'no espírito do professorado'. Promover esta mudança era levar o professor à compreensão das 'novas finalidades sociais' da escola. Mas era também 
fazê-lo percorrer o caminho que leva à superação das velhas concepções sobre a atividade da criança, deslocando-se do território constituído por uma pedagogia centrada no exercício das suas faculdades. Era levá-los a compreender a verdade sobre a natureza infantil, de modo a que pudessem 'praticar realmente a educação funcional' e a realizar, desse modo, a escola ativa (CARVALHO; TOLEDO, 2007, p. 108).

Em Introdução ao estudo da Escola Nova, Lourenço Filho (1929, p. 68-69) faz um extenso retrospecto da história da educação para definir o que denomina de Escola Nova. Em síntese:

Por Escola Nova se deve entender, hoje, um conjunto de doutrinas e princípios tendentes a rever, de um lado, os fundamentos da finalidade da educação; de outro, as bases de aplicação da ciência à técnica educativa. Tais tendências nasceram de novas necessidades, sentidas pelo homem, na mudança de civilização em que nos achamos, e são mais evidentes, sob certos aspectos, nos países que mais sofreram, direta ou indiretamente, os efeitos da conflagração européia. Mas a educação nova não deriva apenas da [1ª] grande guerra. Ela se deve, em grande parte, ao progresso das ciências biológicas, no último meio século, ao espírito objetivo, introduzido no estudo das ciências do homem.

Em Novos caminhos e novos fins, Fernando de Azevedo (1931, p. 57) trata a escola como local privilegiado de transformação social:

Pondo na base as ideias igualitárias de uma sociedade, de forma industrial, em marcha para a democracia e na cúspide da pirâmide revolucionária da reforma, os ideais de pesquisa, de experiência e de ação, quis o Estado preparar as gerações não para a vida, segundo uma representação abstrata, mas para a vida social do seu tempo, sob o regime igualitário e democrático em evolução, transmudando a escola popular não apenas num instrumento de adaptação (socialização), mas num aparelho dinâmico de transformação social.

Fernando de Azevedo aponta a racionalização administrativa e a reformulação pedagógica da escola brasileira como etapas indispensáveis para a construção da sociedade moderna que se pretendia para o país.

Os dois livros apresentados a seguir foram publicados em 1932. Ambos tiveram como referência ou contraponto os livros de Lourenço Filho e Fernando de Azevedo, então recém-lançados. Por não terem sido publicados pela Editora Melhoramentos, ou a Companhia Editora Nacional, nem pela Editora Civilização Brasileira, são razoavelmente desconhecidos. Isto contribuiu na escolha em focalizá-los como possíveis exemplos alternativos das disputas entre leigos e católicos no que se refere à criação de um consenso conceitual de Escola Nova na década de 1930. São as obras Escola Moderna, de Maria dos Reis Campos e A Escola Nova, de Jonathas Serrano.

\section{MARIA DOS REIS CAMPOS E A ESCOLA MODERNA}

Maria dos Reis Campos trabalhou na administração de Fernando de Azevedo como Diretor da Instrução Pública do Distrito Federal, no final da década de 1920. Ela 
exerceu o cargo de Superintendente do Ensino Primário. Segundo Marta Carvalho (2001, p. 84), Maria dos Reis Campos trabalhou também com Anísio Teixeira, quando das reformas educacionais no Rio de Janeiro no início da década de 1930. No prefácio, Maria dos Reis Campos relata que o livro nasceu como resultado de sua estadia, no início de 1930, nos Estados Unidos. Esta viagem foi proporcionada a um grupo de professores ligados à Associação Brasileira de Educação, com o propósito de estudo do Método de Projetos, em voga então naquele país.

O livro Escola Moderna é amplo, com 318 páginas, em nove capítulos. Maria dos Reis Campos, ainda no prefácio, afirma a equivalência entre os termos Escola Moderna e Escola Nova. No primeiro capítulo, a autora faz uma breve explanação sobre o surgimento das escolas elementares no Ocidente, desde a Idade Média até as experiências de Lancaster. No segundo capítulo, em cinquenta páginas, a autora escreve uma história do pensamento educacional desde a modernidade europeia. Os autores por ela selecionados para compor este panorama são apresentados como precursores da escola moderna. Maria dos Reis Campos escreve uma breve biografia dos autores abordados e faz muitas citações literais de trechos de suas principais obras que tratassem de aspectos educacionais ou da criança. Os autores selecionados, na ordem de apresentação do capítulo, são Montaigne, Francis Bacon, Comenius, John Locke, Rousseau, Pestalozzi, Herbart e Froebel.

É no capítulo três que a obra ganha uma estrutura mais coerente com seu tema. Neste capítulo, baseada principalmente em Dewey, mas também com menções esporádicas a Herbart, Froebel e Edouard Claparède, a autora apresenta as características psicológicas das crianças relacionadas à ação, expressão, imaginação, atenção, iniciativa, curiosidade, interesse, capacidade de síntese e cooperação social. Este capítulo serve de espelho ao próximo. No capítulo quatro, a autora destaca que a Escola Moderna, ou Escola Nova, respeita as características psicológicas das crianças. Devido às especificidades da psicologia infantil apresentadas anteriormente, a Escola Moderna trata a criança como criança, e não como um adulto em miniatura. A educação deve preparar a criança para o futuro mundo adulto, contudo:

Preparar o futuro identifica-se, mediante tal conceito, com viver, da melhor maneira, no presente. $E$, para a escola moderna, dado seu respeito pela natureza da criança, viver bem o presente não pode ser senão viver de acordo com essa natureza, com as tendências, com os pendores, com as exigências dessa própria natureza. Surge, então, como finalidade por excelência da escola moderna, favorecer à criança o aproveitamento das oportunidades do presente, isto é, levá-la a viver integralmente como criança (CAMPOS, 1932, p. 108).

O capítulo seis é o mais importante da obra. Nele, a autora descreve o Método Decroly e o Método de Projetos (Dewey/Kilpatrick). Inicialmente, Maria dos Reis Campos (1932, p. 161-162) sintetiza como o método é essencial para a concepção da Escola Moderna:

Criou-se, de tal sorte, nova técnica, destinada, de acordo com o estudo que fizemos no capítulo anterior, a prestar-se essencialmente: 
$1^{\circ}$ - preparar a criança para a vida de adulto, permitindo-lhe ao mesmo tempo viver integralmente como criança, isto é, permitindo-lhe a livre expansão de gostos e tendências naturais;

$2^{\circ}$ - utilizar essas tendências e gostos como meios educativos, atendendo, portanto, a: atividade; liberdade e espontaneidade; iniciativa; interesse espontâneo; imaginação; atenção natural, despertada pelo interesse; curiosidade e espírito de investigação; gosto de imitar; apreensibilidade maior pelo que é concreto e mais fortemente impressiona os sentidos e pelo que é novo; instinto construtivo e de expressão; alegria natural; instintos sociais; e, finalmente, à individualidade;

$3^{\circ}$ - ter em vista a formação mental da criança e não, propriamente, a aquisição de conhecimentos, isto é, visar a educação e não a instrução;

$4^{\circ}$ - utilizar-se de meios os mais objetivos possíveis e particularmente das atividades da vida prática.

Em resumo: tal método deve ser constituído por meios práticos, concretos e naturais, que permitam a expansão das qualidades próprias da criança e as utilizem como instrumento educativo.

Maria dos Reis Campos (1932, p. 170-171) destaca a proximidade com atividades da vida prática como um dos pontos positivos do Método Decroly:

Assentando no tríplice fundamento de: observação, associação e expressão, o ensino se faz em torno de um assunto ou idéia principal que é, por assim dizer, um grande centro de interesse, tomado para um ano de trabalho: a defesa contra inimigos e perigos, por exemplo; em torno desse centro se agrupam outros centros secundários (meios de defesa da criança, a defesa e os animais etc.), destes, por sua vez, decorrem assuntos mais especializados, que podem ser considerados como centros menores e assim sucessivamente.

A matéria fica, de tal sorte, ligada toda entre si, visto como observando, associando e depois dando expressão a idéias e conceitos que se lhe formaram no cérebro, vai a criança adquirindo noções e exercitando o espírito, através de todas as disciplinas que o programa primário comporta.

No programa Decroly há sistematização rigorosa e grande sentido de minúcia que parecem dever prejudicar a espontaneidade e oportunidade, qualidades preciosas na escola moderna. Mas o ensino é conduzido com grande vivacidade, com a preocupação dominante da integração na vida prática e através de iniciativa habilmente despertada e orientada, satisfazendo assim largamente aos ideais pedagógicos modernos.

No texto, não há grande diferenciação entre o Método Decroly e o Método de Projetos. Porém, eles são apresentados como distintos devido às suas diferentes bases teóricas e trajetórias históricas. Sobre o Método de Projetos, inspirado nas idéias de Dewey e de Kilpatrick, a autora define o que entende por projeto:

O que se considera como "projeto" é um trabalho (no sentido mais amplo do termo) planejado e conduzido segundo diretriz previamente assentada e desenvolvido em seu ambiente próprio, de modo que os alunos encontrem aí um símile das atividades da vida real e desenvolvam correspondentemente, não só as qualidades úteis à sua vida presente, mas também as desejáveis no futuro homem e futuro cidadão. Pelo método de projetos pretende-se, antes de mais nada, 
Leigos e católicos em disputa ...

transplantar para a escola o aspecto mais característico da vida prática, que é o de traçar, em maior ou menor escala, um plano e realizá-lo (CAMPOS, 1932, p. 182).

\section{A autora complementa sua caracterização de projeto:}

De modo que, para o projeto, há duas exigências essenciais: $1^{\text {a }}$ - que haja um fim traçado, um plano segundo o qual se desenvolva o trabalho empreendido até sua realização; $2^{\mathrm{a}}$ - que o trabalho se realize em condições naturais, isto é, como na vida real. Para que esta segunda exigência seja satisfeita há uma condição primordial: é que o projeto nasça de uma necessidade sentida pelos alunos, necessidade que lhes despertará o interesse pelo trabalho, dando-lhes gosto por ele, fazendo-os integrar-se em seu verdadeiro sentido e servindo-lhes ao mesmo tempo de guia para o plano de execução que hajam de traçar (CAMPOS, 1932, p. 183).

Maria dos Reis Campos apresenta o Método de Projetos como algo que comporta uma experiência ampla ao aluno. Na execução do projeto, os diversos conteúdos curriculares poderiam ser melhor desenvolvidos no processo educacional. $\mathrm{O}$ Método de Projetos se constituiria em metodologia educacional mais apropriada para as novas necessidades da Escola Moderna, formando o caráter da criança de maneira indelével:

O projeto é justamente essa miniatura e experiência da vida. Por ele se defronta a criança com uma necessidade, que a ela se apresenta como um problema para resolver. Estuda esse problema em seus diversos aspectos. Recolhe informações e assenta um plano no qual se baseia todo o trabalho que daí por diante se realiza. Coleciona material e põe em execução o plano concebido. Há aí: $1^{\circ}$ - verificação de uma necessidade, como impulso para o trabalho; $2^{\circ}$ - estudo dos meios de realização; $3^{\circ}$ - realização de acordo com diretriz pré-fixada. É assim a vida, e nela vencem os que sabem melhor compreender as necessidades de ação; os que melhor sabem adaptar os meios aos fins; e os que, sem desfalecimento, conseguem levar a termo a obra iniciada. O projeto é, de tal sorte, antes de mais nada, uma escola de caráter, de firmeza de vontade, de persistência, de hábito de realizar - tudo isso tomando a criança como criança, porque lhe permite a natural expansão da individualidade, através de trabalho que ela própria escolheu, que lhe desperta o maior interesse e em que encontra, portanto, a mais completa satisfação (CAMPOS, 1932, p. 187).

A autora é incapaz de conceber como algo análogo ao Método de Projetos a execução e administração por parte dos alunos dos projetos em pleno funcionamento nos grupos escolares do período. A cooperativa escolar, o banco escolar, o jornal escolar, o cinema escolar, a cooperativa agrícola escolar, o empório escolar, a organização de acervos e compra de livros de literatura infantil para as bibliotecas escolares e as atividades ligadas ao escotismo não constam no livro de Maria do Reis Campos como exemplos do Método de Projetos. No entanto, a autora não deixa de fornecer quatro exemplos, para que este método seja melhor compreensível com tais ilustrações. A 
autora elabora quatro propostas: $1^{\mathrm{a}}$ - a estação da estrada de ferro; $2^{\mathrm{a}}$ - o trem; $3^{\mathrm{a}}$ - a viagem; $4^{\mathrm{a}}$ - a cidade do Rio de Janeiro. São projetos consecutivos, prevendo atividades extra-escolares, que poderiam atravessar os quatro anos do ensino primário. Contudo, a autora ressalta que são apenas exemplos para favorecer a compreensão do que se propõe como Método de Projetos.

Escola Nova, para esta autora, seria uma releitura da educação renovadora dos Estados Unidos adaptada para a experiência educacional brasileira. A modernização da sociedade brasileira espelharia, portanto, a modernidade alcançada com o exemplo da educação norte-americana. O Método de Projetos seria a chave definidora da Escola Nova. O Método de Projetos poderia ser transposto para outras esferas sociais, quer sejam educacionais, econômicas ou políticas, corroborando para a modernização da realidade brasileira.

\section{A IGREJA CATÓLICA E A ESCOLA NOVA}

Na década de 1930, ocorreu entre os intelectuais católicos brasileiros uma divisão de posições frente a Escola Nova. A ala mais radical encontrava-se no Centro Dom Vital, no Rio de Janeiro. O órgão de divulgação de suas ideias, a revista mensal $A$ Ordem, combatia frontalmente a Escola Nova. Seu principal expoente era Alceu Amoroso Lima. "Sua posição no debate pedagógico brasileiro, sobretudo nos anos 30, foi de um severo combate aos princípios filosóficos da Escola Nova". (CARVALHO; CARVALHO, 2014, p. 53)

Em 1931, o livro de Alceu Amoroso Lima, Debates Pedagógicos, é um ataque contundente à Escola Nova:

Alceu Amoroso Lima publica em 1931 os Debates Pedagógicos. Logo no prefácio da obra propõe a necessidade de uma revolução espiritual, face ao perigo dos ideais do modernismo agnóstico. Para ele, os postulados evolucionistas e positivistas da modernidade serviam para desmembrar a unidade cristã pois, considerando aqui o campo educacional, os liberais defensores da escola ativa e laica pregavam um ensino sem finalidade, ou seja, esses renovadores da educação só se preocupavam em instruir utilizando-se do método, deixando de lado a formação espiritual.

Outra questão relevante refere-se a defesa do direito de primazia para a família e a Igreja sobre o Estado, devendo cada uma dessas esferas agir de acordo com seu campo de atuação. Sendo assim, segundo Alceu, a educação religiosa veiculada pela Igreja Católica constituía a base de toda filosofia, ciência e arte pedagógica e, o contrário, o monopólio da educação nas mãos do Estado como dispunham os escolanovistas, atentava contra a ordem natural e divina das coisas (CARVALHO; CARVALHO, 2014, p. 54).

Nem todos os pensadores católicos brasileiros foram tão radicais. O grupo de intelectuais ligados à Revista Brasileira de Pedagogia, órgão da Confederação Católica Brasileira de Educação, tentou dialogar com alguns dos postulados da Escola Nova. Um de seus expoentes, Leonardo Van Acker, defendia a utilização instrumental da metodologia de ensino da Escola Nova: 
Van Acker alertava que era necessário consultar a encíclica Divini Illius Magistri, do papa Pio XI, de dezembro de 1929, acerca da educação cristã da juventude. Para ele e de acordo com a encíclica, nem tudo podia ser aproveitado da Escola Nova. Recomendava, então, que se aproveitasse o que ela tinha de bom, tanto na disciplina como nos métodos (PINHEIRO; MENESES, 2015, p. 135).

Até a década de 1920, não existia grande animosidade ou conflitos entre católicos e leigos no que se refere aos preceitos renovadores da Escola Nova. O divisor de águas foi a publicação no último dia de 1929 da encíclica Divini Illius Magistri, de Pio $\mathrm{XI}$ :

No Brasil dos anos vinte, a difusão das novas ideias pedagógicas não gerou divisões no movimento educacional. A partir de 1929, a encíclica Divini Illius Magistri altera radicalmente esta situação, impondo limites à heterodoxia pedagógica e regrando a sedução que o escolanovismo vinha exercendo nos meios católicos. O embate doutrinário no campo da Pedagogia torna-se estrategicamente central na disputa pelo controle da escola que se instala a partir de 1930, com a reorganização do Estado e a redefinição da correlação de forças políticas (CARVALHO, 1994, p. 74-75).

Não se pretende aqui analisar detalhadamente esta encíclica, que reafirmava o primado da Igreja Católica frente a família ou o Estado, na educação ou nos demais processos de organização social. Contudo, é apropriado um breve destaque de poucos de seus pontos, que possibilitaram brechas para que alguns intelectuais pudessem usála na apropriação católica da Escola Nova.

Na apresentação, a encíclica explica quais os motivos de sua publicação:

$\mathrm{Na}$ verdade, nunca como nos tempos presentes, se discutiu tanto acerca da educação; por isso se multiplicam os mestres de novas teorias pedagógicas, se excogitam, se propõem e discutem métodos e meios, não só para facilitar, mas também para criar uma nova educação de infalível eficácia que possa preparar as novas gerações para a suspirada felicidade terrena (PIO XI, 1929, p. 2).

Resumidamente, esta encíclica expõe a posição católica sobre quatro pontos básicos:

Para não errar nesta obra de suma importância e para dirigir do melhor modo possível, com o auxílio da graça divina, é preciso ter uma idéia clara e exata da educação cristã nas suas razões essenciais, a saber: a quem compete a missão de educar, qual o sujeito da educação, quais as circunstâncias necessárias do ambiente e qual o fim e a forma própria da educação cristã (PIO XI, 1929, p. 3).

O rápido desenvolvimento da nova indústria cultural do período amedrontava a cúpula da Igreja Católica:

Na verdade nos nossos tempos torna-se necessária uma vigilância tanto mais extensa e cuidadosa, quanto mais têm aumentado as ocasiões de naufrágio moral e religioso para a juventude inexperiente, especialmente nos livros ímpios e licenciosos, muitos dos quais diabolicamente espalhados, a preço ridículo e 
desprezível, nos espetáculos do cinematógrafo, e agora também nas audições radiofônicas, que multiplicam e facilitam toda a espécie de leituras, como o cinematógrafo e toda a sorte de espetáculos. Estes potentíssimos meios de vulgarização que podem ser, se bem dirigidos pelos sãos princípios, duma utilidade para a instrução e educação, aparecem infelizmente, na maior parte das vezes, como incentivos das más paixões e da avidez do lucro. [...] São pois dignas de louvor e incremento todas as obras educativas que, com espírito sinceramente cristão de zelo pelas almas dos jovens, atendem com determinados livros e publicações periódicas, a tornar conhecidos, especialmente aos pais e educadores, os perigos morais e religiosos muitas vezes traiçoeiramente insinuados nos livros e espetáculos, e se consagram a difundir boas leituras e a promover espetáculos verdadeiramente educativos, criando até, com não pequenos sacrifícios, teatros e cinematógrafos em que a virtude não só não tenha nada a perder, mas até muito a ganhar (PIO XI, 1929, p. 25).

Uma de suas partes, frequentemente utilizada contra a Escola Nova pelos intelectuais católicos radicais, é a concepção de juventude, bastante negativa, contida nesta encíclica. Destacava-se que a criança também partilhava do pecado original. $O$ naturalismo pedagógico característico da Escola Nova, ao ignorar que a criança é inerentemente pecadora, seria inapropriado à educação cristã:

A estultícia está no coração da criança e a vara da disciplina dali a expulsará. Devem-se, portanto, corrigir as inclinações desordenadas, excitar e ordenar as boas, desde a mais tenra infância, e sobretudo deve iluminar-se a inteligência e fortalecer-se a vontade com as verdades sobrenaturais e os auxílios da Graça, sem a qual não se pode, nem dominar as inclinações perversas, nem conseguir a devida perfeição educativa da Igreja, perfeita e completamente dotada por Cristo com a divina doutrina e os Sacramentos, meios eficazes da Graça. É falso, portanto, todo o naturalismo pedagógico que, na educação da juventude, exclui ou menospreza por todos os meios a formação sobrenatural cristã; é também errado todo o método de educação que, no todo ou em parte se funda sobre a negação ou esquecimento do pecado original e da Graça, e, por conseguinte, unicamente sobre as forças da natureza humana.

Tais são na sua generalidade aqueles sistemas modernos, de vários nomes, que apelam para uma pretendida autonomia e ilimitada liberdade da criança, e que diminuem ou suprimem até, a autoridade e a ação do educador, atribuindo ao educando um primado exclusivo de iniciativa e uma atividade independente de toda a lei superior natural e divina, na obra da sua educação (PIO XI, 1929, p. 16-17).

Entretanto, isto não implica uma contradição entre a razão e a fé:

A Fé e a razão não só não podem contradizer-se nunca, mas auxiliam-se mutuamente, visto que a reta razão demonstra os fundamentos da Fé, e iluminada pela sua luz, cultiva a ciência das coisas divinas, ao passo que a Fé livra e protege dos erros a razão e enriquece-a com vários conhecimentos. Por isso a lgreja está tão longe de se opor à cultura das artes e das disciplinas humanas que até auxilia e promove, porque não ignora nem despreza as vantagens que delas provêm para a vida da humanidade e até ensina que elas, assim como provêm de Deus, Senhor das ciências, assim também, se tratadas retamente, conduzem a Deus com a sua Graça. E de nenhum modo ela proíbe que tais disciplinas, cada uma na sua esfera, 
usem do método e princípios próprios, mas reconhecida esta justa liberdade, provê cuidadosamente a que não caiam em erro, opondo-se aventurosamente à doutrina divina, ou ultrapassando os próprios limites, ocupem e revolucionem o campo da Fé (PIO XI, 1929, p. 16).

Encontra-se aqui uma das possibilidades de interpretação católica da Escola Nova. Nada impede "que tais disciplinas, cada uma na sua esfera, usem de método e princípios próprios", desde que não se oponham à doutrina católica. O termo chave é "método". Pode-se aproveitar o método da Escola Nova, mas na aplicação de uma educação católica. A encíclica retorna a esta possibilidade:

O professor cristão seguirá o exemplo das abelhas, que das flores colhem a parte mais pura, deixando o resto. [...] E esta necessária cautela [...] não impede de modo nenhum que o mestre cristão acolha e aproveite quanto de verdadeiramente bom produzem os nossos tempos na disciplina e nos métodos, lembrando do que diz o Apostolo: Examinai tudo: conservai o que é bom. Acolhendo, pois, o que é novo, terá o cuidado de não abandonar facilmente o antigo (PIO XI, 1929, p. 24).

Acolher o novo, sem abandonar o antigo, este era o desafio dos intelectuais católicos frente à Escola Nova. A ponte entre o antigo e o novo tornou-se a metodologia de ensino da Escola Nova. Um bom exemplo de como isto foi equacionado no Brasil no início da década de 1930 é o livro A Escola Nova, de Jonathas Serrano.

\section{JONATHAS SERRANO E A ESCOLA NOVA}

Em 1932, quando da publicação deste livro, Jonathas Serrano era professor catedrático de História Universal no Colégio Pedro II e ex-diretor da Escola Normal do Distrito Federal. Já em seu prefácio, a obra de Jonathas Serrano se apresenta como intervenção contrária ao Manifesto dos Pioneiros da Educação Nova, que antecede em poucos meses ao lançamento do livro. Manifesto que o autor se recusou a assinar, devido ao caráter leigo dado à educação neste texto. $\mathrm{O}$ autor defende que a educação deve estar subordinada à religião. Citando Houvre, Jonathas Serrano (1932, p. 12-13) apresenta uma hierarquia no papel educacional:

Toda a delicadeza do problema da educação está nesse respeito do indivíduo sem prejuízo da coletividade. Com razão reclama um pedagogo filósofo: 'No ideal que visam a educação e a formação, importa salientar com energia a distinção de que o homem é mais do que um ser profissional, social, sexual e cidadão. A sociabilidade deve subordinar-se à personalidade; esta, à moralidade, que por sua vez se subordina à religiosidade'. Sem esta hierarquia de valores, a obra educativa é falha e amiúde contraproducente.

Com esta hierarquia, a pedagogia não deve interferir naquilo que em cada indivíduo é inalienável e sagrado: 
A pedagogia sistematiza os princípios que devem dirigir a obra educacional, permitindo a adaptação do indivíduo às condições do meio social, sem sacrifício, todavia, daquilo que no próprio indivíduo é inalienável e sagrado (SERRANO, 1932, p. 12).

Em diversas partes do livro, o autor criticará os erros dos escolanovistas que exageram na abordagem científica da educação e ignoram sua subordinação à metafísica, isto é, à religião:

Já começamos aqui a entrever um dos graves equívocos de certos pedagogos e filósofos da educação. A influência perturbadora do cientificismo revela-se em múltiplas faces: exagerações do naturalismo, do psicologismo, do socialismo. Na essência é tudo um: o erro de querer transformar um indicativo em um imperativo. Este erro de conjugação, porém, não se limita ao domínio da inteligência. $\mathrm{Na}$ gramática da vida, qualquer engano dessa ordem é de consequências graves para o indivíduo e para o próprio meio social (SERRANO, 1932, p. 17-18).

O autor dedicará o capítulo quarto de sua obra a detalhar e combater cada um dos erros da Escola Nova resumidos na citação anterior. Jonathas Serrano apresenta a subordinação da educação à religião como algo que compõe a tradição brasileira desde os primórdios da colonização. Segundo o autor, para uma educação completa, é necessária uma filosofia completa, que não pode prescindir da religião:

Se é exato que uma pedagogia completa supõe uma filosofia completa, uma visão da vida em suas perspectivas morais e religiosas, um conceito integral do homem e de seu destino definitivo - como esperar que possa porventura realizar satisfatoriamente as exigências todas dessa pedagogia um sistema educacional deliberadamente agnóstico, ou apenas leigo, mas em qualquer dos casos incapaz de ver na criança o homem concreto, ainda em formação, sem dúvida, porém, já com as suas tendências mais profundas, entre as quais a de ordem religiosa (SERRANO, 1932, p. 106).

Entretanto, Serrano (1932, p. 29) não atribui à Escola Nova em si os erros de alguns de seus defensores. Propõe, então, outra Escola Nova, uma Escola Nova católica:

Não deixemos, por isso mesmo, que os incrédulos, agnósticos ou fanáticos de outros credos filosóficos ou meramente científicos, nos excedam em perícia técnica, ou espírito de iniciativa no campo experimental.

Jonathas Serrano passa a identificar a Escola Nova católica como sinônimo de didática renovada, perfeitamente adaptável aos princípios da educação religiosa. Marta Carvalho (2001, p. 71-72) sintetiza esta apropriação católica do conceito de Escola Nova:

As estratégias editoriais dos dois grupos em confronto são bastante diferenciadas, como decorrência das apropriações que diferencialmente fizeram da pedagogia escolanovista, entendendo que determinadas proposições pedagógicas eram mais adequadas do que outras a seus projetos de intervenção escolar. Enquanto os pioneiros atuaram no sentido de determinar o significado das expressões educação nova e escola nova, amarrando-o a iniciativas de reorganização da cultura e da 
sociedade de que faziam parte políticas de reforma estrutural da escola e do sistema escolar, os católicos agiram em direção oposta. Procuraram confinar o uso da expressão ao campo doutrinário da pedagogia, de modo a instanciar o discurso pedagógico católico como poder de julgar acerca dos preceitos escolanovistas, evitando que sua introdução nas escolas tivesse impacto transformador esperado pelos seus adversários.

Essa diferença é de extrema importância para a determinação das estratégias editoriais de difusão do escolanovismo. Ela aponta não somente para diferenças nos dispositivos discursivos de legitimação ou censura de proposições escolanovistas, mas também para diferenças de estratégia no tocante à seleção do tipo de material a ser impresso. Para os católicos, o impresso foi sobretudo dispositivo de constituição de um lugar de autoridade para censurar os princípios doutrinários e as práticas escolanovistas de seus adversários e para construir e legitimar um discurso escolanovista católico que ganhasse a adesão do professorado.

O livro A Escola Nova, de Jonathas Serrano, é bom exemplo desta estratégia católica. Ao identificar a Escola Nova, necessariamente subordinada à religião, como apenas método de renovação didática, o autor pode então opinar sobre todas as partes do livro, mencionado anteriormente neste texto, Introdução à Escola Nova, de Lourenço Filho, no que dizem respeito à renovação de métodos didáticos ali contidos. É o que Jonathas Serrano faz, propondo alternativas equilibradas onde identifica exageros de Lourenço Filho. Jonathas Serrano encerra sua obra com novos ataques ao ateísmo cientificista de alguns reformadores educacionais e combate diretamente o Manifesto dos Pioneiros da Educação Nova. Jonathas Serrano, na conclusão de sua obra, conclama os professores católicos a uma urgente "renovação dos métodos de ensino, com sólida base psicológica, [mas] sem exageros fanáticos de escolas, fugindo aos extremos prejudiciais da rotina emperrada e das imprudências revolucionárias". (SERRANO, 1932, p. 137) Ele apresenta a Escola Nova católica como alternativa equilibrada aos extremismos de alguns reformistas ateus, que almejavam com a Escola Nova reformar a sociedade.

Para Jonathas Serrano, paradigma de intelectual católico a interpretar a Escola Nova como metodologia didática moderna, sem extremismos agnósticos, a sociedade brasileira deveria se modernizar sem radicalismos: o novo em conjunção com o antigo, como recomendara Pio XI. Seria uma modernização cautelosa. A metodologia didática da Escola Nova estaria sob incumbência da educação católica. A Igreja Católica se constituiria como o cerne da modernização do país. Sinteticamente, a Igreja Católica seria a ponte entre o novo e o antigo; entre o moderno e o arcaico; entre a razão e a fé; entre o pecado original e a graça; enfim, entre o homem e Deus.

\section{CONSIDERAÇÕES FINAIS}

Os conflitos entre Pioneiros e Católicos apresentaram-se com toda a força quando dos debates da Assembleia Nacional Constituinte de 1934: 
A cizânia entre os renovadores e os católicos teria como palco de radicalização maior o plenário da Constituinte de 1934. Abertamente em oposição, os dois grupos em confronto viriam a expor com nitidez suas divergências e confluências quanto ao lugar social a ser assumido pela educação na teia da nacionalidade brasileira (BOTO, 1990, p. 303).

Na Assembleia Constituinte de 1934, ficariam mais explícitas as propostas divergentes para a nova estruturação do Brasil:

Os debates polêmicos travados no plenário constituinte a propósito do tema educação, priorizavam, fundamentalmente, duas questões: a possível introdução do ensino religioso facultativo nas escolas públicas e - o que julgamos ser ainda mais relevante - os aspectos atinentes à expansão das oportunidades escolares, em todos os desdobramentos que tal medida pudesse acarretar (gratuidade, obrigatoriedade, Plano Nacional de Educação etc.). Assim, por um lado, houve a Liga Eleitoral Católica lutando pelo que entendia como retomada do poder da Igreja nos assuntos temporais, concebidos como negócios de Estado. De fato, a tentativa de introduzir obrigatoriamente nas escolas públicas matéria de teor religioso (ainda que, aos alunos, se propusesse a frequência facultativa) representou um passo dado em direção ao restabelecimento do compromisso entre Estado e Igreja, abalado com a instauração da República. Por outro lado, no debate acerca da extensão da escolaridade básica para todas as camadas da população, encontra-se o pólo aglutinador de um projeto tácito: o reordenamento da feição nacional. A mística de uma unidade cultural era subjacente à priorização, por parte dos constituintes, do temário educacional como dever impreterível do novo Estado que então se construía (BOTO, 1990, p. 362-363).

É apropriado relacionar as diferentes concepções de Escola Nova no início da década de 1930 e os debates constituintes de 1934 sobre o papel da educação no Brasil, mas esta é outra história. As disputas entre intelectuais que defendiam o primado de um Estado leigo e intelectuais católicos frente à definição conceitual do que era a Escola Nova na década de 1930 expõem exemplarmente os embates culturais, sociais e políticos do período. Projetos de país se consolidavam em torno das visões conflituosas do que seria a Escola Nova. Na verdade, discutia-se o que deveria ser o Brasil. Dependendo do que se concebia como Escola Nova, constatava-se o que deveria ser o país. Poucas vezes a concepção de educação e a construção da nacionalidade estiveram tão intrinsecamente conectadas. Com o estudo de tais relações é possível vislumbrar as interfaces entre educação, religião e política. llumina-se a atuação dos intelectuais brasileiros na edificação de distintos projetos de país. A partir de 1937, com o Estado Novo, tais propostas conflitantes foram autoritariamente equacionadas. 
LAY AND CATHOLIC PEOPLE IN DISPUTE FOR NEW SCHOOL IN BRAZIL IN THE 1930s

ABSTRACT: In Brazil, the ideas of the New School were presented as propitious to a modern country. However, what was meant by New School? In the New School configuration, two groups gained clarity: the intellectuals with a lay attitude towards society and the intellectuals linked to the Catholic Church. Two works of teacher training, of 1932, are examples of political differences in dispute. In the current work, the lay conception of New School will be approached by Maria dos Reis Campos' book, Modern School. The Catholic conception will be approached by Jonathas Serrano's book, The New School. The methodology used was the documentary analysis of the two books to be approached. The objective of this work was to provide an understanding of the historical context when the intellectual and institutional divergences on the concept of New School in Brazil of the 1930s.

KEYWORDS: Catholic education. Secular education. New School. History of Education.

\section{LAICOS Y CATÓLICOS EN DISPUTA POR LA ESCUELA NUEVA EN BRASIL EN LA DÉCADA DE 1930}

RESUMEN: En Brasil, las ideas de la Escuela Nueva fueron presentadas como propicias a un país moderno. Sin embargo, ¿qué se entendía por Escuela Nueva? En la configuración de la Escuela Nueva, dos grupos ganaron nitidez: el de los intelectuales con una postura laica frente a la sociedad y el de los intelectuales ligados a la Iglesia Católica. Dos obras de formación pedagógica, de 1932, son ejemplares de las divergencias políticas en disputa. En el actual trabajo, se abordará la concepción de Escuela Nueva laica contenida en el libro Escuela Moderna, de Maria dos Reis Campos. La concepción católica será tratada con el libro La Escuela Nueva, de Jonathas Serrano. La metodología utilizada fue la de análisis documental de los dos libros a ser abordados. El objetivo del trabajo fue de propiciar la comprensión del contexto histórico cuando de las divergencias intelectuales e institucionales sobre la conceptualización de Escuela Nueva en Brasil de la década de 1930.

PALABRAS CLAVE: Educación católica. Educación laica. Escuela Nueva. Historia de la Educación.

\section{REFERÊNCIAS}

AZEVEDO, Fernando de. Novos caminhos e novos fins. São Paulo: Cia. Ed. Nacional, 1931.

BOTO, Carlota Josefina Malta Cardoso dos Reis. Rascunhos de escola na encruzilhada dos tempos. Dissertação de Mestrado. São Paulo: FE-USP, 1990.

CAMPOS, Maria dos Reis. Escola Moderna. Rio de Janeiro: Livraria Francisco Alves, 1932.

CARVALHO, Carlos Henrique de; CARVALHO, Luciana Beatriz de Oliveira Bar de. Intelectuais católicos no espaço luso-brasileiro: as contribuições de Alceu Amoroso Lima 
CELESTE FILHO, $M$.

e António Durão (1930-1950). Cadernos de História da Educação, v. 13, n. 1, p. 47-63, jan./junho de 2014.

CARVALHO, Marta Maria Chagas de. Fernando de Azevedo, pioneiro da Educação Nova. Revista do Instituto de Estudos Brasileiros, n. 37, p. 71-79, 1994.

CARVALHO, Marta Maria Chagas de. A Escola Nova e o impresso: um estudo sobre estratégias editoriais de difusão do escolanovismo no Brasil, p. 65-86. In: FARIA FILHO, Luciano Mendes de. Modos de ler-formas de escrever: estudos de história da leitura e da escrita no Brasil. Belo Horizonte: Autêntica, 2001.

CARVALHO, Marta Maria Chagas de Carvalho. Lourenço Filho e a Biblioteca de Educação: uma estratégia editorial de introdução da Escola Nova no Brasil. Anais del VI Congreso Iberoamericano de Historia de la Educación Latinoamericana. San Luís Potosi, México, 2003.

CARVALHO, Marta Maria Chagas de; TOLEDO, Maria Rita. Os sentidos da forma: análise material das coleções de Lourenço Filho e Fernando Azevedo, p. 89-110. In: OLIVEIRA, Marcus. Cinco estudos em história e historiografia da educação. Belo Horizonte: Autêntica, 2007.

LOURENÇO FILHO, Manuel Bergstrom. Introdução ao estudo da Escola Nova. São Paulo: Melhoramentos, 1929.

PINHEIRO, Maria de Lourdes; MENESES, Maria Cristina. Pragmatismo e idealismo: o debate entre Pioneiros e Católicos em dois manuais no Brasil dos anos 1930. História da Educação, v. 19, n. 45, p. 127-139, jan./abril de 2015.

PIO XI. Divini Illius Magistri:acerca da educação cristã da juventude. Vaticano, 31 de dezembro de 1929. Disponível em <http://w2.vatican.va/content/piusxi/pt/encyclicals/documents/hf_p-xi_enc_31121929_divini-illius-magistri.html > Acesso em 15 set. 2018.

SERRANO, Jonathas. A Escola Nova. Rio de Janeiro: Editor Schmidt, 1932.

TOLEDO, Maria Rita. Coleção Atualidades Pedagógicas. do projeto político ao projeto editorial (1931-1981). Tese de Doutorado. São Paulo: PUC-SP, 2001.

TOLEDO, Maria Rita. Os dispositivos editoriais da coleção Atualidades Pedagógicas e seu projeto de formação do educador. Anais del VI Congreso Iberoamericando de Historia de la Educación Latinoamericana. San Luís Potosi, México, 2003.

TOLEDO, Maria Rita. O projeto político cultural da coleção Atualidades Pedagógicas, p. 335-350. In: DUTRA, Eliana de Freiras; MOLLIER, Jean-Yves. Política, nação e edição:o lugar dos impressos na construção da vida política. São Paulo: Annablume, 2006. 
MAcioniro Celeste FillHO: Possui Bacharelado em História pela Faculdade de Filosofia, Letras e Ciências Humanas da Universidade de São Paulo - FFLCH-USP (1989); Licenciatura em História pela Faculdade de Educação da Universidade de São Paulo - FEUSP (1989); Mestrado em Educação pela Pontifícia Universidade Católica de São Paulo - PUC-SP (2002) e Doutorado em Educação, ambos na área de especialização em História da Educação, pela Pontifícia Universidade Católica de São Paulo - PUC-SP (2006); Pós-doutorado no Instituto de Educação da Universidade de Lisboa (2017); Pós-doutorado na Pontifícia Universidade Católica de São Paulo - PUC-SP (20162017). Atualmente é Professor Assistente Doutor no Departamento de Educação da Faculdade de Ciências da UNESP, campus de Bauru. É professor permanente do Programa de Pós-graduação em Docência para a Educação Básica, da Faculdade de Ciências da UNESP, campus de Bauru. É professor permanente do Programa de Pósgraduação em Educação, da Faculdade de Filosofia e Ciências da UNESP, campus de Marilia.

ORCID: http://orcid.org/0000-0001-8798-9891

E-mail: marciocelestefilho@gmail.com

Este periódico utiliza a licença Creative Commons Attribution 3.0, para periódicos de acesso aberto (Open Archives Iniciative - OAI). 